Imagens em Endocrinologia

\title{
Uma Causa Rara de Insuficiência Suprarrenal
}

\author{
Joana Maciel ${ }^{\mathrm{a},}$, Helder Simões ${ }^{\text {a }}$ \\ a Serviço de Endocrinologia do Instituto Português de Oncologia de Lisboa Francisco Gentil, Lisboa, Portugal
}

INFORMAÇÃO SOBRE O ARTIGO

\section{Historial do artigo:}

Received/ Recebido: 2020-04-29

Accepted/Aceite: 2020-06-05

Final: 2021-01-19

(C) Autor (es) (ou seu (s) empregador (es)) e Revista SPEDM 2020. Reutilização permitida de acordo com CC BY-NC. Nenhuma reutilização comercial.

C) Author(s) (or their employer(s)) and SPEDM Journal 2020. Re-use permitted under CC BY-NC. No commercial re-use.

Palavras-chave:

Linfoma não Hodgkin;

Neoplasias das Glândulas Suprarrenais.

\section{A Rare Cause of Adrenal Insufficiency}

\section{Keywords:}

Adrenal Gland Neoplasms;

Lymphoma, Non-Hodgkin.
Introdução

O linfoma não Hodgkin (LNH) primário da suprarrenal (SR) constitui menos de 1\% de todos os casos de LNH. ${ }^{1}$ Entre os LNH, o linfoma difuso de grandes células B é o mais frequentemente identificado. ${ }^{2}$ O linfoma primário da SR é mais comum no sexo masculino e é bilateral em cerca de $70 \%$ dos casos, podendo condicionar insuficiência suprarrenal.

\section{Caso Clínico}

Apresentamos o caso de um doente do sexo masculino de 68 anos, com antecedentes de malária, asma, hipertensão essencial e colecistectomia. $\mathrm{O}$ doente foi inicialmente observado num hospital geral por queixas consumptivas, nomeadamente perda ponderal, febre, náuseas, vómitos, mialgias e dor abdominal. Realizou estudos complementares que revelaram hiponatrémia de $135 \mathrm{mmol} / \mathrm{L}$ [valor de referência (VR) 136-145) e bacteriémia a Streptococcus sanguis multissensível. Cumpriu antibioterapia e efectuou uma tomografia computorizada (TC) toraco-abdomino-pélvica (Fig. 1) que demonstrou lesões bilaterais nas $\mathrm{SR}$, sólidas, homogéneas e de densidade intermédia ( $76 \mathrm{~mm}$ à esquerda e $55 \mathrm{~mm}$ à direita).

Uma semana depois mantinha queixas consumptivas, tendo recorrido ao serviço de urgência com quadro de hipotensão, hiperpigmentação mucocutânea e hiponatrémia grave (121 mmol/L) que motivou internamento hospitalar. Os níveis de potássio encontravam-se no limite superior da normalidade $[5,0 \mathrm{mmol} / \mathrm{L}$ (VR 3,5-5,1)]. Foi requisitado estudo complementar que sugeriu provável insuficiência da SR: cortisol sérico de $1,4 \mathrm{ug} / \mathrm{mL}$ (VR 6,2-19,4), ACTH de 327 pg/mL (VR 7-63), actividade da renina plasmática de 4,1 $\mathrm{ng} / \mathrm{mL} / \mathrm{h}$ (VR 0,6-4,2) e aldosterona sérica de 0,9 ng/dL (VR 4-31). A 32 microglobulina foi de $13,9 \mathrm{mg} / \mathrm{L}$ (VR 0,8-2,20) e o IGRA (interferon gamma release assay) foi negativo.

Tendo em conta os achados foi instituída terapêutica com hidrocortisona e fludrocortisona, com posterior melhoria clínica e analítica.

Nesta fase o doente realizou PET (positron emission tomography)-FDG (fluorodesoxiglicose)/TC que confirmou captação nas duas lesões das SR com SUVmáx (maximum standardized uptake values) 21,4 à direita e 20,5 à esquerda, sugerindo assim malignidade (Fig. 2). O exame também demonstrou captação em gânglios intra-abdominais (SUVmáx 9,1) e no testículo esquerdo (SUVmáx 7,6). Considerando a elevada suspeita de malignidade, o doente foi transferido para o nosso centro oncológico, tendo sido submetido a biópsia da SR, após doseamento negativo de metanefrinas urinárias. $\mathrm{O}$ exame histológico demonstrou um linfoma difuso de grandes células B com imunohistoquímica a marcar para CD20 e com Ki67 de 70\% (Fig. 3).

O doente iniciou quimioterapia, tendo cumprido 8 ciclos de rituximab, ciclofosfami- .joapinheiro.m@gmail.com (Joana Maciel) nstituto Português de Oncologia de Lisboa, Rua Professor Lima Basto, 1099-023, Lisboa, Portugal 


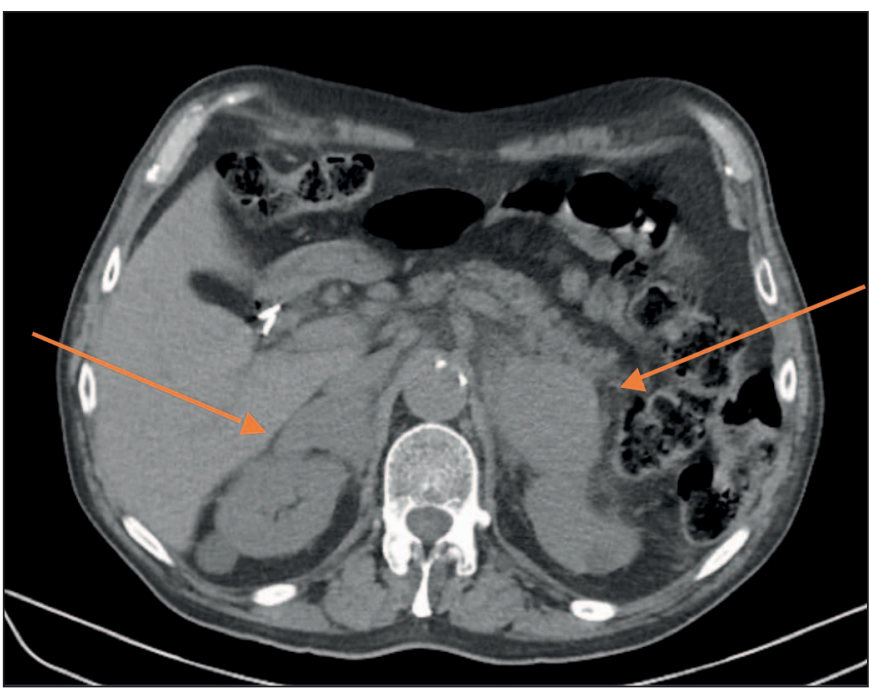

Figura 1. TC toraco-abdomino-pélvica: Supra-renais infiltradas por lesão nodular (setas) medindo $76 \mathrm{~mm}$ à esquerda e $55 \mathrm{~mm}$ à direita. Nódulos sólidos, homogéneos, de densidade intermédia.

TC- tomografia computorizada.

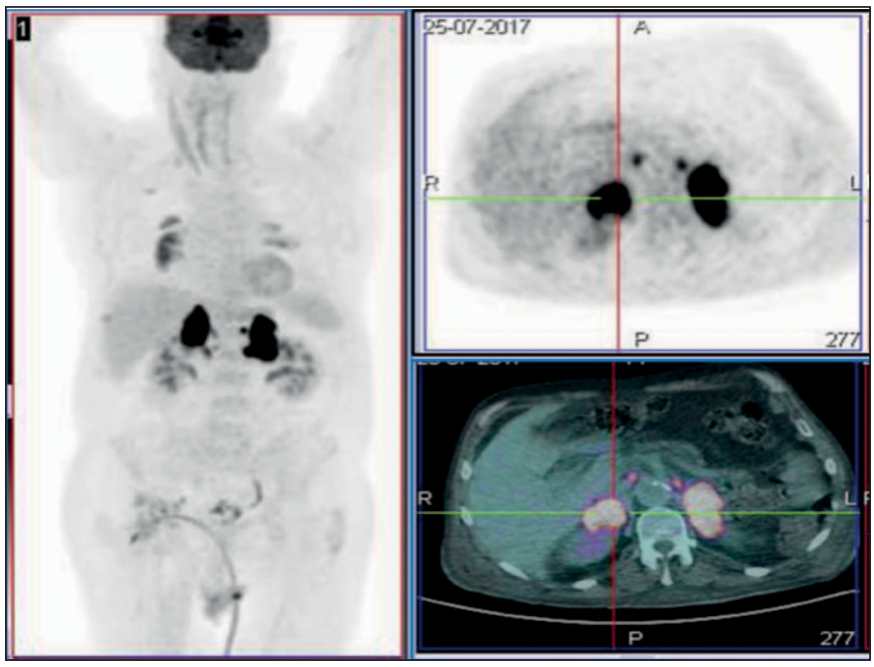

Figura 2. PET-FDG/TC: Captação intensa na supra-renal direita (SUV máx 21,4) e esquerda (SUV máx 20,5), em gânglios intra-abdominais e no testículo esquerdo.

PET - positron emission tomography; FDG: fluorodesoxiglicose; TC- tomografia computorizada; SUV máx-Maximum Standard Uptake Value.

da, doxorrubicina, vincristina e prednisolona e 2 ciclos de metotrexato em alta dose.

Um ano depois, a PET-FDG/TC confirmava doença em remissão, sem captação sugestiva de malignidade. Do ponto de vista da insuficiência da SR não houve reversibilidade do quadro, persistindo actualmente a necessidade de terapêutica de substituição com hidrocortisona e fludrocortisona.

Conclusão

Este caso retrata uma das mais raras causas de insuficiência adrenal: o linfoma difuso de grandes células B. Apesar de rara, esta entidade deve ser considerada no diagnóstico diferencial de massas na SR, sobretudo se bilaterais e captantes em PET-FDG. Atendendo ao impacto no tratamento e prognóstico, este é um dos poucos casos em que é importante a realização de biópsia da SR.

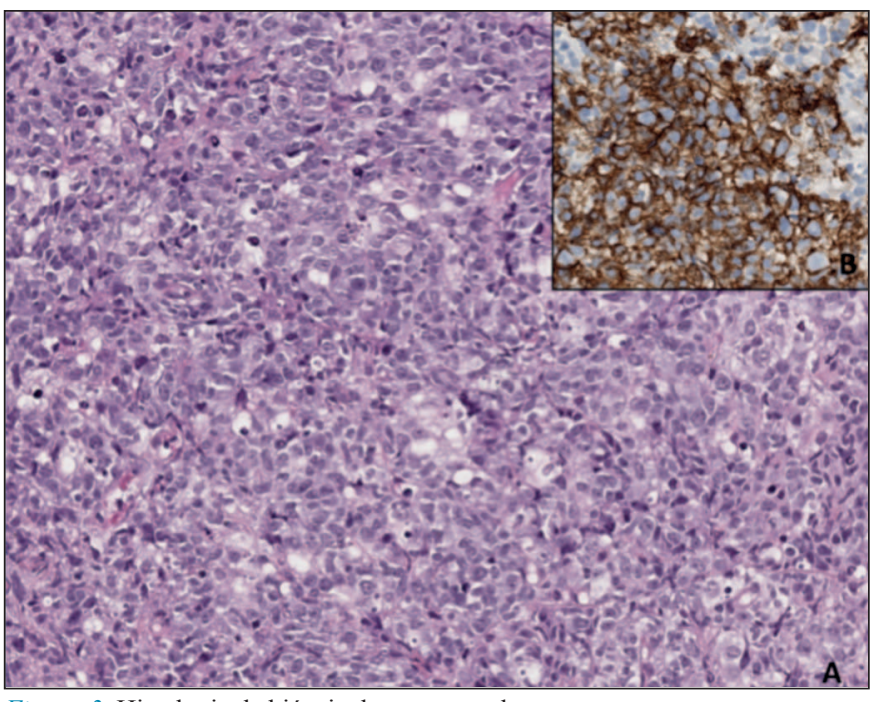

Figura 3. Histologia da biópsia da supra-renal.

A: Hematoxilina e eosina: linfoma difuso de grandes células-B, "non-germinal center". B: Perfil de Imunohistoquímica: CD20+, CD3-, CD5-, CD10-, BCL6+, MUM1+, BCL2+, MYC-. Ki67: 70\%.

\section{Responsabilidades Éticas}

Conflitos de Interesse: Os autores declaram a inexistência de conflitos de interesse na realização do presente trabalho.

Fontes de Financiamento: Não existiram fontes externas de financiamento para a realização deste artigo.

Confidencialidade dos Dados: Os autores declaram ter seguido os protocolos da sua instituição acerca da publicação dos dados de doentes.

Consentimento: Consentimento do doente para publicação obtido. Proveniência e Revisão por Pares: Não comissionado; revisão externa por pares.

\section{Ethical Disclosures}

Conflicts of Interest: The authors have no conflicts of interest to declare.

Financing Support: This work has not received any contribution, grant or scholarship.

Confidentiality of Data: The authors declare that they have followed the protocols of their work center on the publication of data from patients.

Patient Consent: Consent for publication was obtained.

Provenance and Peer Review: Not commissioned; externally peer reviewed.

References / Referências

1. Laurent A, Casasnovas O, Martin L, Chauchet A, Ghesquieres H, Aussedat $\mathrm{G}$, et al. Adrenal lymphoma: presentation, management and prognosis. QJM. 2017; 110:103-9. doi: 10.1093/qjmed/hcw174.

2. Chen P, Jin L, Yang Y, Ni L, Yang S, Lai Y. Bilateral primary adrenal diffuse large B cell lymphoma without adrenal insufficiency: A case report and review of the literature. Mol Clin Oncol. 2017; 7:145-7. doi: 10.3892/ mco.2017.1264.

3. Rashidi A, Fisher S. Primary adrenal lymphoma: a systematic review. Ann Hematol. 2013; 92:1583-93. doi: 10.1007/s00277-013-1812-3.

4. Ekhzaimy A, Muhamammi A. Bilateral primary adrenal lymphoma with adrenal insufficiency. BMJ Case Rep. 2016: bcr2016217417. doi: 10.1136/bcr-2016-217417 